\title{
A RESSIGNIFICAÇÃO DO FEMININO NA CONTEMPORANEIDADE EM BARBAZUL, DE ANABELLA LÓPEZ
}

\section{THE REFRAMING OF THE FEMALE IN CONTEMPORANEITY IN BARBAZUL, BY ANABELLA LÓPEZ}

Recebido: 15/04/2021

Aprovado: 06/07/2021

Publicado: $30 / 07 / 2021$

DOI: $10.18817 /$ rlj.v5i01.2584

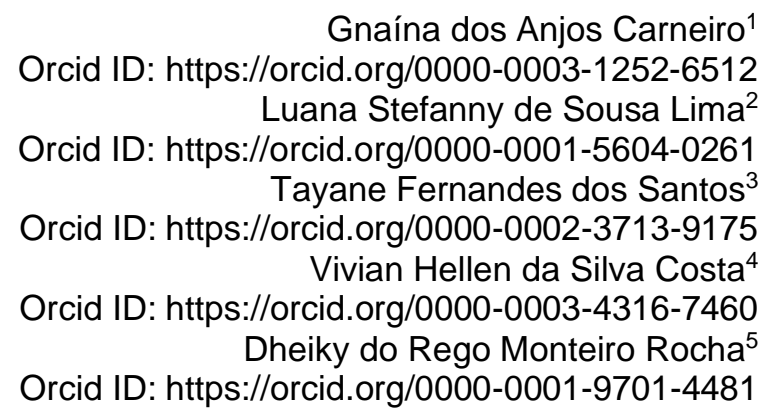

Resumo: O objetivo deste artigo é analisar no conto Barbazul (2017), de autoria da escritora e ilustradora Anabella López, a representação da mulher na sociedade patriarcal, considerando os contextos sócio-históricos do conto clássico matriz - adaptado pelo francês Charles Perrault - e da releitura contemporânea, bem como descrever a figura da mulher, dando ênfase ao comportamento feminino por meio dos elementos estruturais da narrativa. Para alcançar o objetivo proposto, mobilizam-se algumas contribuições teóricas e críticas de Candido (2002), Ceccantini (2011), Bozzetto Júnior (2009), Andruetto (2012) e Zolin (2005). A leitura do texto literário aponta que o protagonismo das personagens Barbazul e sua esposa representam a transfiguração de traços de referência à realidade no trato às condições de opressão sofridas pela mulher, numa perspectiva de ruptura das submissões do gênero feminino, promovidas pelo patriarcalismo. A obra literária Barbazul evidencia uma ressignificação do feminino, por meio de uma reelaboração estética na literatura, que humaniza e emancipa os leitores pressupostos crianças e jovens.

Palavras-chave: Literatura infantil e juvenil. Conto de fadas. Barbazul. Representação da mulher.

\footnotetext{
${ }^{1}$ Graduanda em Letras Licenciatura em Língua Portuguesa e Literaturas de Língua Portuguesa, pela Universidade Estadual do Maranhão (UEMA), Campus Timon. E-mail: gnaina701@gmail.com

${ }^{2}$ Graduanda em Letras Licenciatura em Língua Portuguesa e Literaturas de Língua Portuguesa, pela Universidade Estadual do Maranhão (UEMA), Campus Timon. E-mail: stefanny1172@gmail.com

${ }^{3}$ Graduanda em Letras Licenciatura em Língua Portuguesa e Literaturas de Língua Portuguesa, pela Universidade Estadual do Maranhão (UEMA), Campus Timon. E-mail: tayanefernandesdossantos@gmail.com

${ }^{4}$ Graduanda em Letras Licenciatura em Língua Portuguesa e Literaturas de Língua Portuguesa, pela Universidade Estadual do Maranhão (UEMA), Campus Timon. E-mail: viviandasilva2112@gmail.com

${ }^{5}$ Mestre em Letras, Especialista em Literatura Brasileira e Licenciado em Letras Português, pela Universidade Estadual do Piauí (UESPI). Professor provisório no curso Letras Licenciatura em Língua Portuguesa e Literaturas de Língua Portuguesa da Universidade Estadual do Maranhão (UEMA), no Centro de Estudos Superiores de Timon - CESTI. Membro do grupo de pesquisa Estudos Interdisciplinares em Literatura e Linguagem - LITERLI, da UEMA, na linha de pesquisa Literatura e Sociedade, cadastrado no Diretório dos Grupos de Pesquisa no Brasil do CNPq. E-mail: dheiky@yahoo.com.br
} 
Abstract: The objective of this article is to analyze in the short story Barbazul (2017), authored by the writer and illustrator Anabella López, the representation of women in patriarchal society, considering the socio-historical contexts of the classic story matrix - adapted by the French author Charles Perrault - and from contemporary reinterpretation, as the same time as to describe the female figure emphasizing the feminine behavior through the structural elements of the narrative. To achieve the proposed objective, we combine some theoretical and critical contributions from Candido (2002), Ceccantini (2011), Bozzetto Júnior (2009), Andruetto (2012) and Zolin (2005). The reading of the literary text points out that the protagonism of the characters Barbazul and his wife represents the transfiguration of reference features to the reality in dealing with the conditions of oppression suffered by women in a perspective of disruption of female submissions promoted by patriarchy. The literary work Barbazul highlights a reframing of the feminine through an aesthetic reelaboration on literature, that humanizes and emancipates the presupposed readers children and youth.

Keywords: Children's and youth literature. Fairy tale. Barbazul. Representation of women.

\section{Introdução}

Ao longo da história da humanidade, o patriarcalismo influenciou diretamente no comportamento das mulheres, pressupondo assim seus papéis sociais, no âmbito privado (dentro de casa) e público (fora de casa). Desse modo, sendo a literatura uma arte que transfigura o real e veicula aspectos da condição humana, por meio do estético e do imaginário, é pertinente evidenciarmos a forma como a mulher é tratada pela visão e ação da dominação patriarcal, que ainda vigora na contemporaneidade. $\mathrm{Na}$ atualidade, os leitores crianças e jovens têm a possibilidade de ter contato com obras literárias que propiciam reflexões acerca de questões que estão no cerne da vida social. Nesse sentido, os leitores preferenciais, lidando com o fictício e o imaginário, permitem-se a conhecer narrativas que potencializam a abertura de novas visões de mundo, que se articulam como uma atualização necessária à formação do homem e da mulher, sem que haja um caráter panfletário. Em face dessa contextualização, este estudo tem como objetivo analisar a representação da mulher na sociedade patriarcal e descrever a figura feminina, dando ênfase ao comportamento da mulher por meio dos elementos estruturais da narrativa no conto adaptado Barbazul (2017), de autoria da escritora e ilustradora argentina Anabella López, numa perspectiva dinamizadora da narrativa que humaniza e emancipa o sujeito sócio-histórico.

A motivação para a realização deste estudo surgiu a partir da leitura da obra clássica adaptada, que tem sua origem na tradição oral, na qual é possível observar a presença de várias temáticas. No entanto, a temática que mais nos despertou a atenção fora a forma relevante que a autora argentina retrata a mulher na sociedade 
patriarcal, sob uma releitura engendrada de potenciais interpretações plausíveis que coadunam com as ressignificações acerca das configurações atuais do feminino.

Para tanto, realizamos um estudo de abordagem qualitativa e bibliográfica, com suporte teórico e crítico baseado em autores como Lúcia Osana Zolin (2005), no que concerne aos conceitos relacionados aos ideais patriarcais que moldam o comportamento da figura feminina; além das contribuições de André Bozzetto Júnior (2009), María Teresa Andruetto (2012) no que concerne às implicações do período social, histórico e cultural na produção de uma obra literária e em relação aos ideais da qualidade de um livro literário, respectivamente, entre outros.

Anabella López é uma notável escritora e ilustradora de livros da literatura infantil e juvenil do século XXI. Ela nasceu na Argentina, mas mora no Brasil desde o ano 2013. A autora conta com mais de 20 livros publicados em diversos países, como Argentina, Brasil, México, EUA, Canadá, França e Emirados Árabes. Algumas obras de Anabella López possuem autoria integral, ou seja, a autora exercendo a função de escritora e ilustradora ao mesmo tempo, como em Outros mundos (2017), Um coelho (2017), entre outras. Atualmente, a sua produção artística é predominantemente voltada para a ilustração. O trabalho da autora é reconhecido internacionalmente e à obra Barbazul (2017) foram concedidos os seguintes prêmios: Prêmio Cátedra 10, Selo Distinção, outorgado pela Cátedra Unesco de Leitura PUC-Rio, em 2017, e o Prêmio FNLIJ (Fundação Nacional do Livro Infantil e Juvenil) 2018 - Produção 2017, na categoria Tradução/Adaptação Reconto.

Dessa forma, a ressignificação do feminino frente a uma sociedade patriarcalista, representada no conto Barbazul, na autoria integral de Anabella López, constitui-se de uma adaptação que promove um encontro do artístico e do literário, sob o signo da ilustração e da palavra. A discussão acerca de tal tema mostra-se importante pela possibilidade de promover a reflexão e a conscientização de crianças, jovens e leitores em geral sobre as formas de opressão contra a mulher na sociedade. Diante disso, as interpretações possíveis a partir da leitura da obra literária podem auxiliar na desconstrução de concepções equivocadas, em que os atos de violência contra a mulher, sejam de ordem física, moral ou psicológica, não sejam considerados como normais nas relações sociais.

Nessa perspectiva, a produção literária de Anabella López traz o encantamento na narrativa verbal e visual para crianças e jovens, numa integração dinamizadora entre imagem e texto escrito, delineando os processos de 
autoconhecimento e de conhecimento do mundo, afastando-se de um caráter funcional que o livro possa promover na leitura, prevalecendo o valor estético, e ao mesmo tempo jogando luzes em questões existenciais e sociais emergentes, que são indispensáveis à emancipação do pensamento contemporâneo. Assim, os leitores preferenciais têm a oportunidade de adentrar no universo ficcional em busca da construção dos significados e sentidos.

\section{Literatura e representação do feminino na sociedade patriarcal}

De acordo com Zolin (2005, p. 183), o patriarcalismo refere-se a "uma espécie de organização familiar originária dos povos antigos, na qual toda instituição social concentrava-se na figura de um chefe, o patriarca, cuja autoridade era preponderante e incontestável". Tal configuração social que se remonta dos primórdios da humanidade, ainda se faz presente, em pleno século XXI, na sociedade, implicando na opressão que a mulher sofre cotidianamente.

Segundo os ideais patriarcais, a figura feminina é tida como inferior à masculina, sendo dependente desta última para "ser vista" e ter algum status social. Assim, nessa perspectiva, não é permitido à mulher questionar e criticar as imposições que lhes são feitas, e sim, resignar-se frente às tais determinações, sob pena de serem punidas por insurgirem-se contra o modelo social vigente. A partir da análise do livro Barbazul, de Anabella López, publicado pela editora Aletria (Fig.1), pode-se perceber tais articulações com relação à representação comportamental da figura feminina.

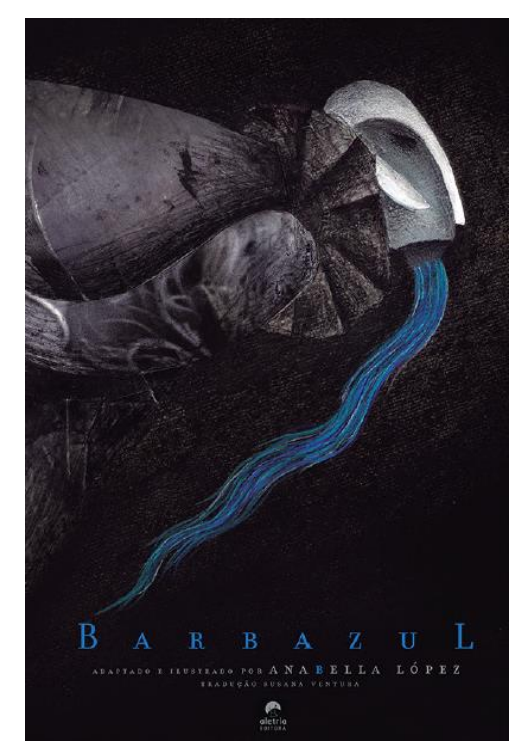

Fig. 1 - Capa do livro ilustrado Barbazul.

Fonte: Editora Aletria (LÓPEZ, 2017). 
No referido livro, Anabella López traz uma adaptação de um conto clássico "O Barba Azul", primeiramente escrito pelo francês Charles Perrault, sendo resultado do seu trabalho de coleta de contos e lendas da Idade Média, no século XVII, fazendo parte dos chamados contos de fadas. Em sua releitura, Anabella López incorpora à história algumas novidades que serão abordadas mais à frente, na análise da obra. Essas novidades estão atreladas à conjuntura do pensamento feminino que o momento sócio-histórico possa suscitar.

As adaptações de um livro de literatura estão intrinsecamente relacionadas ao contexto de sua produção. Em artigo intitulado "Moralidade e fantasia: as versões clássicas de 'Chapeuzinho Vermelho' e seus leitores pressupostos", Bozzetto Júnior (2009) faz uma breve análise acerca de como os contextos histórico, social e cultural influenciam na escrita, na abordagem e no pressuposto público-alvo de um texto literário. Segundo Bozzetto Júnior (2009), os contos de Perrault tinham a função de entreter e, sobretudo, transmitir lições de moral aos leitores crianças. Assim, aos pressupostos leitores era garantida uma instrução que atendesse à moralidade vigente naquele contexto de formação pessoal, respeitando as normas sociais instauradas para o exercício da virtude e boa conduta.

A partir disso, podemos apontar que os contextos de produção da versão de Perrault e de López são diferentes, pois os aspectos de ordem histórica, social e cultural ganham abordagens destinadas às demandas dos leitores de cada época. A escritora contemporânea está inserida em um contexto em que a mulher começa a tomar consciência da sua posição de subalternização, sendo submissa ao longo dos séculos e busca lutar por reconhecimento de direitos políticos e sociais, fatos ligados, entre outras coisas, ao movimento feminista que se intensificou a partir do século XIX. Já o conto de Perrault foi escrito em um contexto em que a mulher era totalmente desprovida de direito à voz e aos questionamentos sobre sua realidade. Sobre o feminismo, Zolin (2005), esclarece que:

[...] trata-se de um movimento político bastante amplo que, alicerçado na crença de que, consciente e coletivamente, as mulheres podem mudar a posição de inferioridade que ocupam no meio social, abarca desde reformas culturais, legais e econômicas, referentes ao direito da mulher ao voto, à educação, à licença-maternidade, à prática de esportes, à igualdade de remuneração para função igual etc., até uma teoria feminista acadêmica, voltada para reformas relacionadas ao modo de ler o texto literário (ZOLIN, 2005, p. 183). 
Em um círculo social ainda marcado pelas ideias patriarcais, talvez a obra de López não tenha uma boa recepção e aceitação de alguns leitores, acostumados com histórias padronizadas, sem certas inovações e que não se afastam dos padrões vigentes e canônicos, não que essas não mereçam ser valorizadas, é que se deve dar notoriedade a outras formas de fazer literatura que podem ser também apreciadas. Portanto, é lícito promover outras possibilidades de visões de mundo aos leitores crianças e jovens, por meio da literatura, porque propicia a eles uma autonomia na interpretação dos eventos narrativos, que também são transfigurações de referências ao real.

No capítulo "Por uma literatura sem adjetivos" da obra homônima ao capítulo, Andruetto (2012) reflete sobre a qualidade das obras literárias, afirmando que um bom escritor se nega a produzir obras que atendam às exigências do mercado, baseando-se em uma perspectiva de busca pelo estético com qualidade, em que as verdades são um caminho para o conhecimento. Desse modo, entendemos que a literatura provoca novos olhares sobre o mundo, para diversas questões que circundam mulheres e homens. Nesse sentido, observamos que, em Barbazul, López explora a temática da opressão da mulher em um relacionamento de viés patriarcalista, acrescentando um caráter emancipador e humanístico para a ressignificação do feminino, de maneira inovadora. Como atesta Andruetto, a respeito de um olhar sobre o mundo,

\begin{abstract}
A obra de um escritor não pode ser definida por suas intenções, mas por seus resultados. Se há algo em comum entre os bons escritores de diferentes épocas é justamente que eles têm pouco em comum uns com os outros e, às vezes, até se diferenciam fortemente ou se opõem francamente uns aos outros. Surge, então, uma primeira certeza: um bom escritor é um escritor diferente de outros escritores. (ANDRUETTO, 2012, p. 55).
\end{abstract}

Portanto, em Barbazul, inferimos que essa provocação de novos olhares sobre o feminino instaura uma resistência ao patriarcalismo, uma vez que a escritora López se vale em assumir uma distinção na sua narrativa que contraria a uniformização do conto clássico, oferecendo realces e particularidades na produção que a torna diferenciada da escrita de Perrault e de outros escritores em versões produzidas antes da obra dela.

Em se tratando da transformação do conto herdado da tradição oral, Ceccantini (2011) sublinha que esse processo de releitura, ou seja, de novidades 
acrescentadas aos contos de fadas, busca atender aos valores relacionados ao novo pensamento sobre infância e família no Ocidente, tornando essas narrativas mais difundidas entre os leitores pressupostos - o público infantil. Assim, no processo de escrita, e até de ilustração, como é o caso de Anabella López, que atua nessas duas dimensões no livro em questão, a narrativa vai tomando forma de acordo com o que a autora quer dar ênfase de maneira verbal e visual, recriando uma estética que evidencie possibilidades de construção dos sentidos, voltados para o caminho de visões insubmissas a respeito da mulher.

O crítico literário Candido (2002, p. 79) afirma que "[...] é difícil pôr de lado os problemas individuais e sociais que dão lastro às obras e as amarram ao mundo onde vivemos". Embora não tenha compromisso com o real, a literatura pode levar, muitas vezes, o leitor a refletir e questionar sobre determinados aspectos sociais da sua própria realidade, que podem estar refletidos em uma obra. Dessa forma, mesmo que sem intencionalidade, a literatura pode ter um papel de expandir as visões de mundo e configurações de uma dada sociedade, bem como intervir de forma a despertar o leitor sobre determinados aspectos sociais. Nessa perspectiva, o elemento contextual de produção do texto literário não é meramente uma projeção da vida social, mas um elemento constitutivo no engendramento do texto, que, consequentemente, possibilita uma experiência literária que converge com o caráter humanístico, que torna o leitor com uma visão de mundo independente, em torno das questões representadas na literatura.

É sob essa perspectiva de uma função humanizadora na literatura, propalada por Candido (2002) e sincronizada aos outros pensamentos aqui mobilizados, que o nosso estudo recai sobre a ideia de uma projeção da experiência do homem na literatura que possa atuar na sua formação, enquanto sujeito sócio-histórico ativo e autônomo. Portanto, há uma identificação e interesse do leitor com a visão de referência à realidade, trazida à tona pela escritora. Nesse caso, em razão do traço de humanidade constante na narrativa, promovendo uma apropriação do exercício do ficcional com a ação dinamizadora da experiência humana.

\section{A figura feminina em Barbazul: entre a submissão e a ruptura}

Como já explicitado, o livro Barbazul, de Anabella López, é baseado no conto clássico de Charles Perrault. Segundo pontua Ceccantini (2011), esse processo de 
reelaboração dos contos de fadas foi ocorrendo para atender o público infantil durante séculos. Esse procedimento de alteração desses contos é contínuo na história da literatura e ainda perdura na contemporaneidade. Vale ressaltar que esses contos marcam, expressivamente, a presença da figura feminina. Por isso, é necessário o estudo da obra em análise, porque é uma adaptação em que a escritora López oferece uma releitura da sua interpretação a respeito da história consagrada ao longo do tempo. A autora torna mais visível o comportamento submisso padrão da sociedade patriarcal daquela época, possibilitando uma comparação com o contexto atual sobre o pensamento a respeito da mulher, que necessita de uma tomada de consciência do seu valor existencial e social, seja pela própria leitora mulher, seja pelo leitor homem.

A obra Barbazul trata da história de um homem muito rico, mas por outro lado, repugnado pelas mulheres por sua característica peculiar, a barba azul. Certo dia, a personagem conhece uma moça que o aceita. Passando algum tempo de casados, Barbazul informa à esposa que necessita viajar a negócios e antes de partir a deixa com todas as chaves do castelo onde vivem, proibindo-a, no entanto, de abrir um aposento, em particular, pois se o fizer a personagem ficará sabendo de qualquer maneira. Entretanto, a esposa não cumpre o combinado e o marido ao descobrir resolve matá-la. Porém, a punição não ocorre, pois a mulher é salva pelos irmãos que matam Barbazul.

$\mathrm{Na}$ abordagem de López, antecedendo a história em si, o leitor depara-se com uma imagem que provoca uma ambiguidade. Tal figura pode ser interpretada como uma porta ou um caixão. Assim, se os leitores conhecerem a versão de Perrault, eles podem remeter a imagem aos acontecimentos contidos na obra do escritor e interpretar tal "enigma", como a porta que pode levar à morte, em consequência da desobediência feminina, no entanto, não é essa interpretação fechada que se pode fazer, a partir da leitura da reescrita da autora.

Em face da crítica feminista, o comportamento feminino na sociedade patriarcal pode ser caracterizado por dois parâmetros, conforme elenca Zolin (2005, p. 183, grifo da autora): "a mulher-sujeito é marcada pela insubordinação aos referidos paradigmas, por seu poder de decisão, dominação e imposição; enquanto a mulher-objeto define-se pela submissão, pela resignação e pela falta de voz". Nessa perspectiva, desses conceitos operatórios da crítica feminista, nota-se que na obra em estudo a esposa de Barbazul, inicialmente, apresenta-se como uma figura 
passiva e resignada aos preceitos estabelecidos pelo marido, sendo, portanto, uma “mulher-objeto". Podemos constatar esse comportamento no trecho a seguir:

\begin{abstract}
Visite todos os aposentos que desejar, abra e feche quantas portas quiser. Só de uma coisa a proíbo: não entre no quarto do último andar do palácio. Confio em você e sei que saberá respeitar minha proibição. Esta é a chave do quarto proibido e ela é um precioso instrumento mágico: se você abrir aquela porta, não haverá nenhuma maneira de fazer com que esta chave se cale.

Ela prometeu obedecer beijando amorosamente seus lábios e abraçando-o com ternura (LÓPEZ, 2017, p. 10-13).
\end{abstract}

No fragmento acima, nota-se como o discurso do patriarca Barbazul desenvolve-se advertindo a esposa para que não abra a porta de um determinado cômodo da casa, pois se assim ela o fizer não poderá esconder o acontecimento dele. Essa advertência dá-se em um tom de ameaça, disfarçado de confiança que o marido diz ter na esposa, induzindo-a, mesmo que inconscientemente, a obedecê-lo sem questionamentos.

No entanto, a partir do momento em que a esposa desobedece Barbazul e, até mesmo, questiona-se sobre um possível segredo que o marido possa estar a esconder, a mulher, sutilmente, passa para um estágio de "mulher-sujeito", que, porém, é reprimido, resultando na punição que o patriarca Barbazul resolve dar a esposa. Ao quebrar a promessa feita ao marido Barbazul, a mulher chega ao ponto que pode causar mudanças, tanto nela própria como no leitor. Vejamos no trecho a seguir:

Dominada pela curiosidade, não hesitou e subiu as antiquíssimas escadas. $[\ldots]$

A tentação era tão forte que não pode resistir. Parou por um instante, olhou para a chave com medo e, tremendo, finalmente abriu a porta.

Todo o quarto estava em penumbra e, de início, nada vislumbrou. Mas logo, para seu horror, viu que o chão estava completamente coberto de sangue. O mesmo sangue que gotejava dos corpos de várias mulheres mortas penduradas no teto.

Num instante entendeu tudo. Aquelas mulheres haviam sido as esposas anteriores de Barbazul que, como ela, não conseguiram guardar seu segredo (LÓPEZ, 2017, p. 14-19).

A mulher, ao buscar saber o que esconde o quarto proibido, toma conhecimento da realidade opressora em que está inserida, descobrindo os corpos das esposas anteriores, assassinadas por Barbazul. Tal constatação pode ser enfatizada quando somada à significação das imagens contidas no trecho citado. 
Podemos destacar, dessa forma, a configuração das imagens da chave em uma metáfora, uma vez que López representa, primeiramente, como um olho fechado (Fig.2), podendo simbolizar a resignação, a falta de conhecimento acerca da realidade pela esposa. E posteriormente, a partir do ponto em que se adentra a porta do quarto proibido, a autora apresenta a imagem da chave representando um olho aberto (Fig.3), podendo significar, agora, o conhecimento da atitude brutal cometida pelo marido e, sobretudo, a tomada de consciência do valor da figura feminina, a partir de uma situação de horror, que pode levá-la à morte ou ao empreendimento de mudança acerca da realidade. Essa representação simbólica empregada no objeto mágico na narrativa, com o recurso da arte da ilustração, é importante para despertar toda a humanidade sobre a visão de mundo voltada para as questões do universo da mulher, que requer respeito e reconhecimento enquanto partícipe de uma sociedade na contemporaneidade. Vejamos nas imagens a seguir:

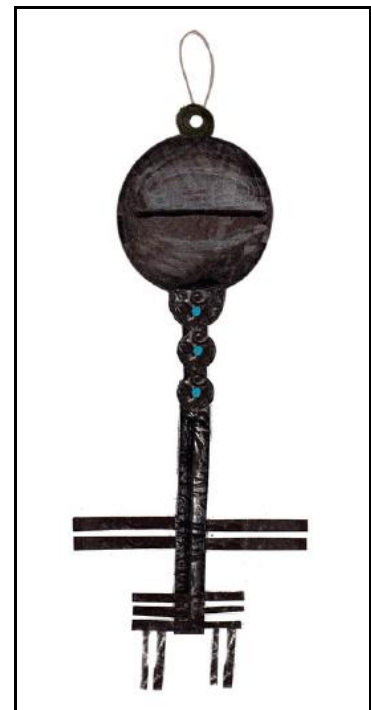

Fig. 2 - Momento da chave mágica, antes da descoberta dos corpos no quarto proibido.

Fonte: Editora Aletria (LÓPEZ, 2017).

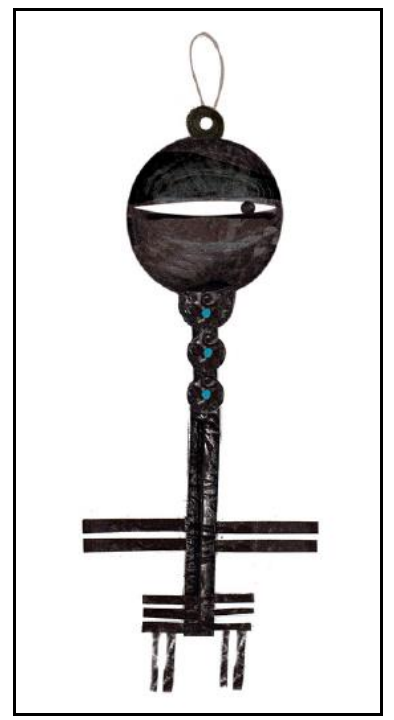

Fig. 3 - Momento da chave mágica, depois da descoberta dos corpos no quarto proibido. Fonte: Editora Aletria (LÓPEZ, 2017).

Na versão de Charles Perrault, o autor apresenta ao final do conto duas morais, transcritas a seguir:

\section{Moral}

A curiosidade, apesar de todos os seus atrativos,

Custa amiúde muitos arrependimentos; 
Vêem-se todos os dias mil exemplos mostrarem.

Trata-se, a despeito do sexo, de um prazer bem rápido;

A partir do momento em que é tomado, deixa de ser,

E sempre custa demasiadamente caro.

\section{Outra moral}

Por menos que se tenha espírito prudente,

E que do mundo se conheça o quebra-cabeças,

Vê-se sem demora que esta história

É um conto do tempo passado;

Não há mais marido tão terrível,

Nem que peça o impossível,

Ainda que seja insatisfeito e ciumento.

Perto da esposa, é visto ficar submisso;

E, seja qual for a cor de sua barba,

É difícil julgar qual dos dois é o senhor.

(PERRAULT, 2005, p. 243, grifo do autor).

Analisando-se a citação da narrativa clássica, produzida em contexto sóciohistórico impregnado de moralidade, podemos inferir que o autor tenta justificar a atitude masculina, colocando a mulher como culpada, por ter um comportamento errôneo, desobedecendo ao marido e deixar-se levar pela curiosidade. No contexto de produção da versão de Perrault, no século XVII, os preceitos patriarcais eram fortemente arraigados na sociedade, mais do que na contemporaneidade. Nessa perspectiva, outro ponto a destacar no fragmento acima, é que o autor afirma que no período da obra em questão, não existem mais maridos violentos e opressores e sim uma igualdade entre os gêneros, sendo até mesmo difícil julgar quem é o "senhor". O que, infelizmente, não é verídico, nem no tempo do plano ficcional do conto e nem nos dias atuais. É notório que, contemporaneamente, a mulher tem ocupado um espaço no meio social, legal e profissional, no entanto, com muita resistência por parte da sociedade ainda permeada por ideais patriarcalistas.

No conto reescrito por Anabella López, entretanto, há uma reivindicação do feminino representado como uma figura que pode construir uma história diferente da que "normalmente" se espera. Essa diferença é notória ao observarmos o desfecho no conto da autora que traz um acontecimento novo, na passagem em que a esposa de Barbazul, em um gesto de manifesto pelas mulheres assassinadas pela personagem, busca em seu jardim um local para sepultá-las.

Dentro dos jardins gelados que rodeavam suas terras, a mulher enterrou as outras esposas do Barbazul para que suas almas descansassem em 
paz. Junto dos túmulos plantou centenas de flores vermelhas, para que todos se lembrassem delas para sempre (LÓPEZ, 2017, p. 33).

É muito interessante como a autora faz uso das combinações entre imagem e texto verbal para uma maior significação literária. Ainda, ao observarmos o final do conto de López, podemos notar como a escritora apresenta a figura feminina (Fig. 4) ao leitor, com um diferencial no comportamento que pode estar carregado de muita ressignificação, valendo-se de acréscimos significativos que levam a narrativa para uma construção de rupturas de padrões sociais cristalizados por séculos, provocando o leitor para o pensar a respeito de uma emancipação feminina.

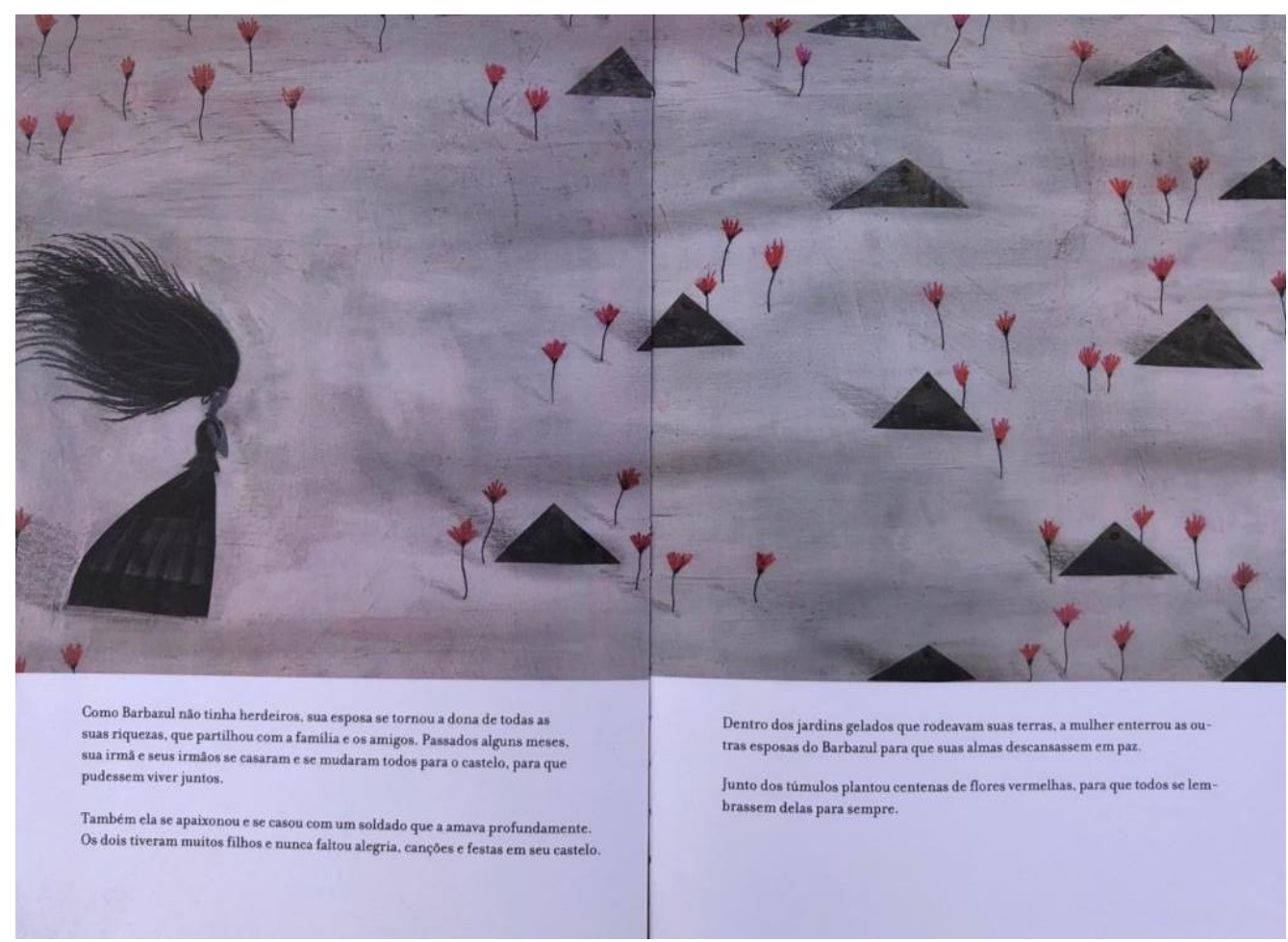

Fig. 4 - Esposa de Barbazul com cabelos soltos no jardim com os túmulos das esposas anteriores. Fonte: Editora Aletria (LÓPEZ, 2017).

$\mathrm{Na}$ imagem do livro em página dupla ilustrada acima, podemos constatar que a mulher está representada com os cabelos soltos e esvoaçantes, entretanto, anteriormente a essa parte final da narrativa, a figura feminina é apresentada com os cabelos sempre presos. Essa atitude dela traça uma nova postura que pode representar, simbolicamente, uma liberdade, uma ruptura com as amarras ideológicas do patriarcalismo, que buscam moldar o comportamento feminino na 
sociedade. Logo, é indubitável que os elementos que compõem uma obra literária podem ter alguma representatividade.

Outrossim, é importante salientar como Anabella López faz uso das cores em seu conto para dar significado à mensagem literária. Em observação às imagens e cores utilizadas durante a narrativa, notamos que são empregados tons escuros suscitando, por exemplo, uma expressiva atmosfera sombria e de horror. Além disso, a cor azul, em particular - convencionalmente associada à figura masculina - é a que se apresenta de forma mais expressiva nas ilustrações, conferindo até um jogo de sedução, podendo enfatizar a predominância da figura masculina sobre a figura feminina. A partir do evento narrativo em que a esposa de Barbazul é salva pelos irmãos, que o derrota com várias lanças no seu corpo, tem-se a marcante presença da cor vermelha, podendo simbolizar o sangue da morte, a derrota do opressor e a vivacidade da resistência e liberdade feminina.

Assim, podemos inferir que a personagem Barbazul e a esposa representam transfigurações de uma realidade, respectivamente, aquele como a categoria de homens opressores, machistas e violentos com mulheres; ela como uma gama de mulheres que, inseridas em uma sociedade permeada pelo patriarcalismo, sofrem diversos tipos de opressão por motivo do seu gênero. Em face da perscrutação empreendida, numa perspectiva da crítica feminista e da função humanizadora na literatura, Barbazul delineia-se como uma obra literária da contemporaneidade, compondo um lastro de narrativas de contos de fadas que contribuem para a ampliação dos horizontes de leitura na convergência para visões e atitudes insubmissas ao patriarcalismo.

\section{Considerações finais}

Neste estudo, podemos concluir que, a princípio, a esposa de Barbazul apresenta-se como uma mulher submissa aos ideais patriarcalistas. Entretanto, no desenrolar da narrativa vemos que a mesma rompe com esses ideais, libertandose de toda a opressão e violência resultante do sistema patriarcalista.

Conforme o pensamento de Candido (2002) e dos outros estudiosos mobilizados para este estudo, a literatura instaura um processo de humanização e 
emancipação porque propicia uma experiência ficcional de contato com referências ao bem e ao mal, como na vida social. Assim sendo, podemos apreender que, embora não tenha uma funcionalidade pedagógica e instrutiva, a literatura pode servir, às vezes, para o vislumbre de mudanças no pensamento da humanidade. Por isso, há o empoderamento da personagem feminina do conto Barbazul, que pode servir de exemplo, saindo do plano ficcional, às mulheres que vivem relacionamentos abusivos, sendo oprimidas pela figura masculina.

Dessa forma, concluimos que a análise da temática em questão no referido conto, possibilita a compreensão da literatura como oportunidade de reflexão e ressignificação social, no tocante às questões contemporâneas que operam a favor da mulher. Sendo assim, a leitura de obras literárias com esse caráter humanizador, direcionada para o público infantil e juvenil, poderá possibilitar o desenvolvimento de uma visão de mundo mais libertária e independente.

\section{Referências Bibliográficas}

ANDRUETTO, María Teresa. Por uma literatura sem adjetivos. Tradução de Carmem Cacciacarro. São Paulo: Editora Pulo do Gato, p. 52-70, 2012.

BOZZETTO JÚNIOR, André. Moralidade e fantasia: as versões clássicas de "Chapeuzinho Vermelho" e seus leitores pressupostos. Revista Litteris. n. 2, maio/2009. Disponível em: https://www.yumpu.com/pt/document/read/12797234/moralidade-e-fantasia-asversoes-classicas-de-chapeuzinho-. Acesso em: 22 jan. 2021.

CANDIDO, Antonio. A literatura e a formação do homem. In: Textos de intervenção. São Paulo: Duas Cidades; Editora 34, p. 77-92, 2002. (Coleção Espírito Crítico).

CECCANTINI, João Luís. Outra vez era uma vez: contos de fadas e literatura infantil brasileira. In: MARTHA, Alice Áurea Penteado. Tópicos de literatura infantil e juvenil. Maringá: Eduem, 2011. (Formação de professores em Letras - EAD; n. 16).

LÓPEZ, Anabella. Barbazul. Belo Horizonte: Aletria, 36 p, 2017.

PERRAULT, Charles. Contos de Perrault. Tradução de Maria Stela Gonçalves. São Paulo: Paulus, 2005.

ZOLIN, Lúcia Osana. Crítica feminista. In: BONNICI, Thomas; ZOLIN, Lúcia Osana. (Orgs.). Teoria literária: abordagens históricas e tendências contemporâneas. 2. ed. Maringá: Eduem, p. 181-203, 2005. 